\title{
El megalito ha muerto. ¡Larga vida al megalito!
}

Marcos Martinón-Torres, Institute of Archaeology, University College London

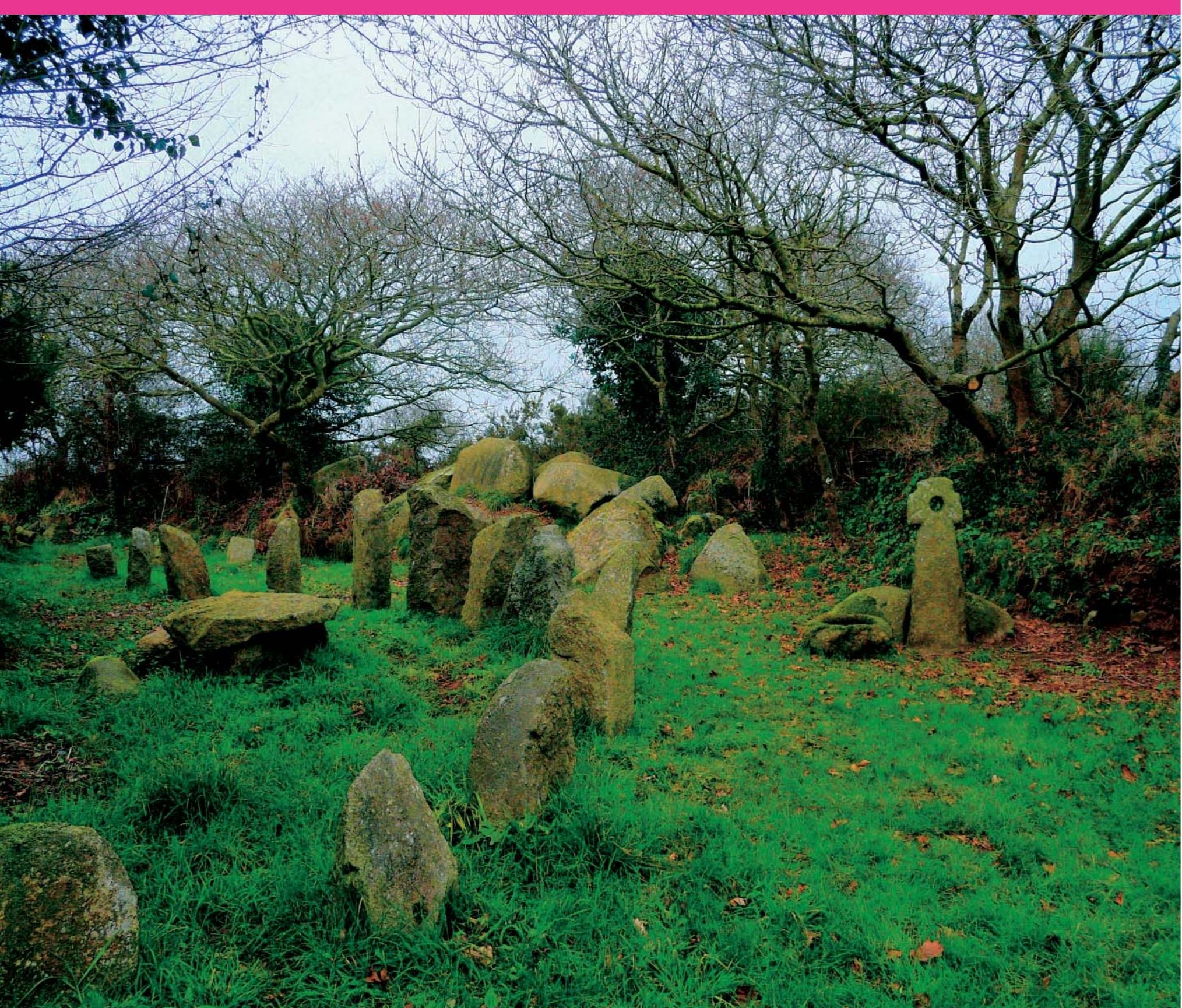


La mayor parte de los estudiosos del megalitismo centran sus esfuerzos en averiguar cómo se erigieron estas estructuras, cómo se empleaban o qué significados tuvieron para las sociedades prehistóricas que los construyeron. En otras palabras, utilizan los megalitos como fuentes de información acerca de los constructores de megalitos. Otros profesionales se encargan de la musealización y puesta en valor de estas construcciones, para facilitar el disfrute público del patrimonio y, en general, la difusión de los resultados de investigaciones arqueológicas. Sólo en épocas más recientes se ha comenzado a estudiar los megalitos como monumentos: el valor monumental de los megalitos reside en que fueron construidos para perdurar; de hecho, muchos de ellos han pervivido y perviven, disfrutando de unas vidas que son mucho más largas que las de sus constructores. Por tanto, no tenemos por qué restringir nuestro estudio a unos cuantos siglos de la Prehistoria Reciente. Las reutilizaciones de algunos megalitos como espacios rituales en épocas muy posteriores a su construcción ponen de manifiesto que sociedades relativamente recientes interactuaron con los viejos monumentos y los mantuvieron vivos, aun cuando sus usos y significados puedan haber cambiado (GARCÍA SANJUÁN, 2005; 2008; GARCÍA SANJUÁN et al., 2007). Si consideramos los megalitos como monumentos cuyas vidas continúan, y de las que somos partícipes, no sólo abrimos nuevas vías para la investigación, sino que también plantearemos retos para las políticas de gestión del patrimonio.

Existe una gran riqueza de fuentes documentales que nos permiten aproximarnos a las vidas de los megalitos y de las gentes que los rodeaban en períodos relativamente recientes. El caso gallego permite ilustrarlo. En trabajos anteriores (MARTINÓN-TORRES, 2001b; 2006) he categorizado los usos y significados de los megalitos en épocas históricas en tres ámbitos interrelacionados: territorial, simbólico e histórico. Probablemente estos tres valores han existido siempre, pero su intensidad parece variar en distintos períodos.
El valor territorial de los monumentos megalíticos es una herencia de sus usos pasados. Como construcciones visibles, los megalitos crearon paisajes culturales, y su función como marcadores de territorios prehistóricos está bien documentada. Sin embargo, el valor territorial de los megalitos no termina en la Prehistoria. Llegados a la Edad Media, existen centenares de contratos agrarios y expedientes de apeos en los que se hace referencia a monumentos megalíticos como marcos de territorio. Cuando se tenían que precisar los lindes de un terreno, era común recurrir a elementos fijos en el paisaje como ríos, caminos, fuentes y, con muchísima frecuencia, túmulos y dólmenes. También existen innumerables topónimos medievales, como Monte da Meda, o Lugar de Mámoas, que muy probablemente aluden a los megalitos que identifican el territorio. El empleo de megalitos como marcos de territorio disminuye a lo largo de la Edad Moderna, probablemente porque muchos han sido destruidos ya, y también por los cambios que tienen lugar en la demarcación de lindes. No obstante, muchos topónimos perduran hasta hoy como vestigios de la antigua presencia de monumentos y su valor territorial (MARTINÓN-TORRES, 2001a).

Percibimos también continuidades en el valor simbólico y ritual de los megalitos, aun cuando sus percepciones hayan evolucionado. Cada vez se documentan más casos de enterramientos en túmulos en épocas muy posteriores a su construcción inicial, lo cual subraya el papel religioso que los monumentos mantuvieron durante siglos. A comienzos de la Edad Media, varios concilios eclesiásticos condenan los cultos paganos a las piedras, que en muchos casos tendrían lugar en monumentos megalíticos. Tenemos incluso documentación de dólmenes que son cristianizados con cruces de piedra y romerías religiosas, o bautizados con topónimos como Mámoa de San Marcos.

Llegados al siglo XVII, documentamos una nueva eclosión del valor simbólico de los monumentos, aunque con un nuevo cariz: según las fuentes es- 
2. Dolmen de Belmez, Córdoba / Foto: M. A. BLanco de La Rubia. Fuente: Empresa Pública de Gestión de Programas Culturales

4. El dolmen de Axeitos en la actualidad: ¿una sepultura, un documento prehistórico, o un lugar de recreo? / FOTO: MARCOS MARTINÓN-TORRES
3-5. Durante el S. XVII se extiende la costumbre de excavar los túmulos en busca de "tesoros perdidos". Dolmen Pedra Arca (Á Coruña) y Dolmen de Chan de Arquiña (Pontevedra) / FOTO: FERNANDO CARRERA RAMIREZ
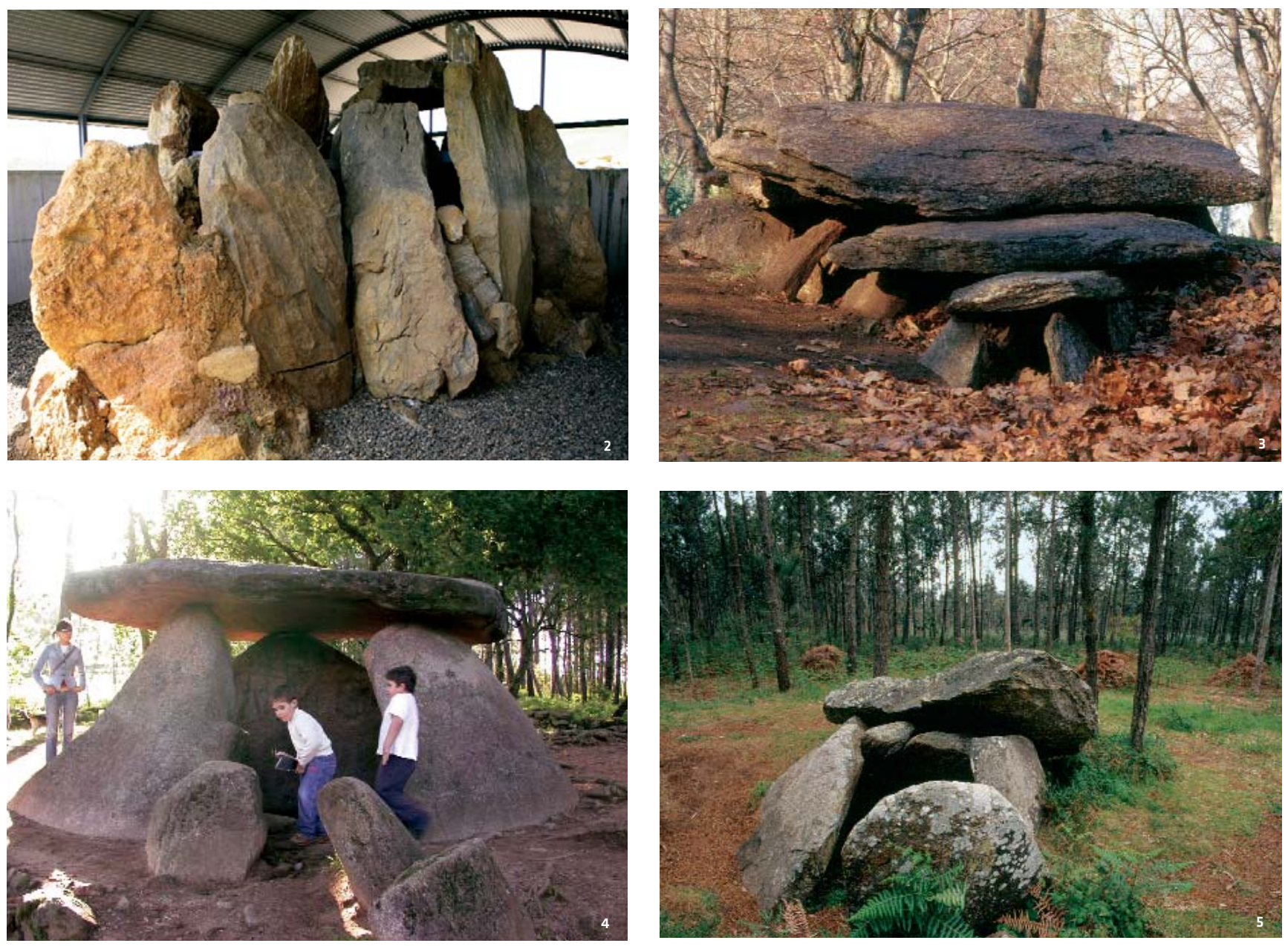

critas, los monumentos se perciben como lugares míticos de encuentros y fenómenos paranormales y, ante todo, como prometedores escondrijos de antiguos tesoros dejados allí por los "gentiles galigrecos". En 1609, el clérigo Pedro Vázquez de Orjas obtuvo una Real Cédula que lo autorizaba a excavar los túmulos gallegos y, a cambio de una jugosa comisión, recuperar para las arcas del reino el oro y la plata que supuestamente escondían. La noticia causó una frenética fiebre del oro que llevó a cientos de paisanos gallegos a excavar furtivamente infinidad de monumentos con la esperanza de encontrar tesoros. Conocemos este episodio por el grueso libro judicial que resultó de los innumerables juicios, acusaciones y defensas que se sucedieron, y en las que encontramos referencias a peleas, insultos y debates legales, además de un largo anecdotario de encuentros míticos, adivinos, amenazas de horcas, supuestos nuevos ricos e inverosímiles hallazgos (MARTINÓN-TORRES 2001b; 2002). Poco importa ya la vieja función de los monumentos como marcos de territorio, sublimada ante las legendarias expectativas de milagros, tesoros y nuevas vidas
El valor histórico de los monumentos megalíticos, es decir, su papel como testimonios de un pasado remoto, sólo se percibe y fomenta a partir de la llustración. Con certeza, sociedades anteriores al siglo XVIII se habrían referido a los megalitos como tumbas o monumentos de períodos remotos, quizás aludiendo a lazos ancestrales. Sin embargo, durante el Medievo y parte de la Edad Moderna no se documenta ninguna referencia a los monumentos como vestigios susceptibles de informar sobre el pasado. Aun cuando se reconocen como "tumbas de paganos", los túmulos no aparecen mencionados en los pioneros libros de historia, ni se hace referencia a ellos en diversos intentos de justificar la singularidad histórica gallega. El interés académico o político por estos monumentos, su apropiación como referentes históricos, sólo surgirá una vez que el fraile ilustrado Martín Sarmiento y otros eruditos comiencen a combatir la "fatua credulidad de los avarientos, ignorantes y ociosos" que se dejaban atrapar por el atractivo simbólico de los túmulos (MARTINÓN-TORRES 2001b). En los libros de historia decimonónicos en- 
contramos interpretaciones celtistas y etnocentristas del fenómeno megalítico que, en cierto modo, parecen tener más de ideología y simbolismo que de rigor académico. Sin embargo, en la voluntad de incluir megalitos en reconstrucciones históricas podemos ver el germen de una percepción de estos monumentos que, en los ámbitos académicos, llega hasta hoy.

Este superficial repaso de las interacciones entre megalitos y sociedades en épocas históricas es tan sólo una muestra de lo mucho que podemos llegar a descubrir si prestamos atención a las largas vidas de los megalitos. Restringir nuestro interés a su infancia no hace justicia a los monumentos, ni a sus constructores, ni a las innumerables personas que, durante siglos, han interactuado e interactúan con ellos. Esta perspectiva nos obliga a replantearnos nuestras políticas y protocolos de gestión del patrimonio megalítico.

Es innegable que los arqueólogos y profesionales del patrimonio, por su formación y titulación, deben ser los principales encargados de estudiar y divulgar nuestra riqueza megalítica. Sin embargo, una perspectiva diacrónica pone de manifiesto que nuestra percepción de estas construcciones como documentos prehistóricos es un fenómeno reciente y, en gran medida, circunscrito al ámbito académico. En sus largas vidas, los megalitos han desempeñado otros papeles, entre los que hemos destacado aquí sus funciones territoriales y simbólicas. Sería fácil ampliar y diversificar este catálogo para incluir otras valoraciones y usos (HOLTORF, 2002-7). Los megalitos han sido y son sepulturas colectivas, marcos de territorio y escondrijos de míticos tesoros. Pero también siguen siendo puntos de inspiración para poetas y pintores, paradas de paseantes, cobijos para pastores, centros de peregrinación paganos, iconos de legitimación política, estorbos para trabajos agrícolas, minas para canteros, viviendas de personajes míticos y un sinfín de posibilidades. Como arqueólogos y profesionales del patrimonio, la ley tiende a privilegiar nuestros enfoques, interpretaciones y usos de estos monumentos. Sin embargo, también hay paseantes, campesinos, neopaganos, jueces, artistas, constructores, políticos, canteros y pensadores desempeñando importantes papeles en las vidas de los monumentos. Desde el momento en que dejamos de utilizar los monumentos como tumbas, su empleo como "fuentes de información prehistórica" es tan sólo una propuesta, no necesariamente más auténtica o legítima que otras.

En los últimos años han empezado a proliferar los centros de interpretación o proyectos de revalorización asociados a monumentos megalíticos. Desde la perspectiva que se argumenta aquí, estos proyectos plantean la oportunidad y el reto de interpretar y revalorizar los monumentos en todas sus dimensiones. Para ello será necesario flexibilizar nuestros enfoques, diversificar nuestras fuentes de información y considerar muchas voces que, en general, han sido desatendidas por los profesionales del patrimonio. Si somos capaces de trascender las barreras de nuestra propia especialización profesional y de deshacernos de nuestra vanidad académica, estaremos más cerca de mantener los megalitos no ya como documentos muertos, sino como monumentos vivos.

\section{Bibliografía}

GARCíA SANJUÁN, L. (2005) Las piedras de la memoria. La permanencia del megalitismo en el Suroeste de la Península Ibérica durante el II y I milenios ANE. Trabajos de Prehistoria, $n^{\circ} 62$ (1), 2005 , pp. 85-109

GARCíA SANJUÁN, L. (2008) Muerte, tiempo, memoria. Los megalitos como memoriales culturales. PH: Boletín del Instituto Andaluz del Patrimonio Histórico, 2008

GARCÍA SANJUÁN, L.; GARRIDO GONZÁLEZ, P.; LOZANO GómEZ, F. (2007) Las piedras de la memoria (II). El uso en época romana de espacios y monumentos sagrados prehistóricos del Sur de la Península Ibérica. Complutum, $n^{\circ}$ 18, 2007, pp $109-130$

HOLTORF, C. (2002-7) Monumental Past. The Life-histories of Me galithic Monuments in Mecklenburg-Vorpommern (Germany) [monografía electrónica]. University of Toronto: Centre for Instructiona Technology Development [http://hdl.handle.net/1807/245]

MARTINÓN-TORRES, M. (2001a) Los megalitos de término: crónica del valor territorial de los monumentos megalíticos a partir de las fuentes escritas. Trabajos de Prehistoria, $n^{0} 58$ (1), 2001, pp. 95-108
MARTINÓN-TORRES, M. (2001b) OS monumentos megalíticos despois do megalitismo. Arqueoloxía e Historia dos megalitos galegos a través das fontes escritas (S. VI-XIX). Valga: Concello de Valga, 2001

MARTINÓN-TORRES, M. (2002) Defying God and the King: a 17 thcentury gold rush for megalithic treasure. Public Archaeology, $n^{\circ}$ 2(4), 2002, pp. 220-235

MARTINÓN-TORRES, M. (2006) On the life-histories of megaliths in Northwest Iberia. En Rodríguez Casal, A. A. (ed). The Atlantic Megaliths. Oxford: Archaeopress, 2006, pp. 43-51 (BAR Internationa Series 1521) 